\title{
Gross SAARC Happiness: A Perspective on Ethical Governance
}

\author{
Nirbhay Kumar Mishra \\ GLA University, Mathura, Uttar Pradesh, India \\ E-Mail: nirbhay.mishra@gla.ac.in
}

\begin{abstract}
Since its inception in 1985 South Asian Association for Regional Cooperation (SAARC, hereafter), in the last three decades, has been making painstaking efforts, as a collective forum, to achieve its three basic goals: Economic Development, Good Governance through integrated Regional Cooperation by establishing a platform for the social, environmental and economic development. Despite giving impetus to their regional cooperative mechanism, SAARC has been struggling to achieve the objectives laid down in GNH (Gross National Happiness) a globally followed model developed by the Fourth King of Bhutan, in the 1970s. This paper tries to develop a view point to understand the proposed vision of Gross SAARC Happiness (GSH, hereafter) by putting emphasis on the very idea of development through critical ethical investigation into the various governance ideas adopted by the cooperative nations. One of the aims of this paper is to offer an explanation of the basics of happiness \& development in that the social, environmental, and economic realms of life cannot be subjugated to GDP (Gross Domestic Product) or GNI (Gross National Income). Hence, the index of GSH is entrenched in the sustainable collective development on the one hand and the collective $\&$ individual happiness on the other. What will be crucial in achieving the model of GSH is that the cooperative countries have to practice enhanced political cooperation in maintaining collective peace, and they should refrain from the unsustainable models to achieve GDP. Rather, it is the inclusive growth which should produce individual happiness, collective wellbeing, and Sustainable development. The paper develops the method of ethical governance, by taking recourse to the idea of Sustainable Development Goals structured by the United Nations (UN), for the cooperative nations to adopt as an alternative governance mechanism in achieving the Happiness and Governance at SAARC in the replica of GSH.
\end{abstract}

Keywords: SAARC, Ethical Governance, Governance Mechanism, Sustainable Development, Gross Happiness

\section{INTRODUCTION}

The last SAARC meet in 2014 had the motto to develop a "Deeper integration for peace and prosperity in South Asia." They had clear declarations to intensify the regional cooperation primarily in the areas of socio-economiccultural; trade, finance, infrastructure, peace, prosperity \& culture. Furthermore, the commitment to achieve South Asian Economic Union (SAEU), SAFTA \& trade facilitation, SAARC development fund, Connectivity, Energy and Poverty Elevation Fund. The state leaders worked out on Post-2015 Development Goals as integrated in their upcoming developmental strategies following the UN model of global development to achieve the millennium development goals across the world. In this development agenda they will have a focus on Agriculture \& Food
Security, Environment, Health, Woman \& Children, Youth, Social Protection, Migration, and Science\& Technology, Fighting against terrorism \& trans-national crimes \& Governance. Analyzing the whole developmental strategies $\&$ the SAARC upcoming 20 years perspective, it is quite reasonable to understand that the cooperative community of states have to develop a kind of governance not only putting emphasis on the economic union but also to develop a collective happiness union. The view I have proposed in this paper is to develop the happiness union what I call Gross SARRC Happiness (GSH). My view takes up the exemplary concept of GNH practiced by one of the member states Bhutan. And, the paper theoretically philosophize the possibility of such a concept to be practiced at SAARC in confirming the post-2015 goals on the one hand and sustainable development goals adopted by the UN for the international development model on the other. The paper criticizes the popular idea of gross development product or gross national income. The analysis offers an explanation of development in terms of the human happiness and progress. My view proposes a model that put forth the individual happiness and collective governance to achieve the GSH. The paper opens with a critical investigation into the commonly adopted happiness \& governance mechanisms. The Critical analysis establishes the fact that the developmental ideas concerning the industrial development and infrastructural development, Manufacturing, Goods \& Services are not worthwhile to the human development if they cannot produce sustainable happiness.

\section{CRITICAL ANALYSIS: GOVERNANCE MECHANISM}

William Nordhaus, an economist at Yale University, in his paper looked at two ways of measuring the price of light over the past two centuries. He argues that the GDP figure does not properly reflect the development and progress of the common people. It measures development in an instrumental manner. We need to understand that human development and happiness cannot simply be a conglomeration of produced things and services. In his criticism of the idea of GDP he argues that GDP is a poor way of assessing the prosperity as it does not offer a right picture of how GDP growth enhances the quality of life. The point of the dissuasion is that the happiness cannot be an outcome of the national development achieved through GDP or GNP. Meer Ahsan Habib offers an explanation of the criticism of GDP in the following way: "Imagine a world where you earn a decent living, the state treats you 
with fairness, there is little carbon emission in the environment, and on top of everything else, and the society values your opinion. Who wouldn't want to live in such a utopian world? There is hardly any country in the world that takes into consideration all these indicators to determine whether the country and its people are happy". Most of the time, the debates on peace, prosperity and development have intentionally avoided the much needed dialogue on productive governance to be practiced by the member states. Rodrigo put forward this point: "Avoiding debate on contentious issues between the member states has been a major reason for lack of concrete progress at SAARC. Considering that the role of Asian continent is increasing at global level, increased cooperation between SAARC members and observers, particularly China, holds high rationale. A spirit of equality and mutual benefit needs to be developed. Cooperation between corporate sectors, think tanks and academic institutions, cultural linkages and tackling the challenges of globalization together may usher in a new era of prosperity for the region." The contentious issues involving cross border situations, fake currency, drug trafficking, human trafficking, inter-states security, migration, international violation on the social-economic \& environmental issues must be resolved otherwise SAARC will continue to be criticized for lacking the determination to confront the real issues. The avoidance of governance attitude must change to a due diligence attitude.In the recent meeting held at Islamabad, India has put forth issues like drug trafficking, fake currency, and terrorism. The policy adopted by India in criticizing the artificial distinction between "good terrorism and bad terrorism" is praiseworthy in its intent to combat the menace of terrorism in the while region. Terrorism should be condemned in an unequivocal way and any conceptual imagination to defend it is a threat to collective happiness. A philosophical way of understanding this issue would be to approach it from the angle of what the philosopher Daniel Dennett calls the Intentional Stance: Intentional systems theory is in the first place an analysis of the meanings of such everyday 'mentalistic' terms as 'believe,' 'desire,' 'expect,' 'decide,' and 'intend,' the terms of 'folk psychology' that we use to interpret, explain, and predict the behavior of other human beings, animals, some artifacts such as robots and computers, and indeed ourselves. In view of the Intentional Stance, the political issues of collective importance like terrorism and internal security, migration, drug trafficking and human trafficking require active intentional governance and due diligence.

SAARC is sometimes being criticized for being apolitical in not addressing properly the regional political problems involving the collective interests. The critics who reckon SAARC as an "empty forum" can be adequately answered if the member states take an intentional stance to put the thorny issues in the forefront of discussion and develop a mechanism to figure out solutions for these transnational problems which are murdering the collective happiness of the states. To accomplish this, it is vital that the problems should be recognized as state-neutral and human-centric so that a strategy is evolved cutting across national lines to effectively tackle them. It is in this way alone that SAARC can evolve as a family of collective happiness \& governance. That alone will lead to change the viewpoint on SAARC from an empty to an active forum.

Furthermore, we can focus on two policy trends which have been great barriers in achieving collective happiness, and obstructed the realization of effective governance on certain issues and that have done a great damage to the status of SAARC as a regional cooperative forum: 1) Political Mistrust - that the states in keeping the national sovereignty intact, seldom develop the trust amongst the member states. We can see this lack of trust among most of the member states in their approach to tackling the most problematic issues. Jha so rightly put the point as follows: Core problem areas in south Asia such as environmental degradation have in part been aggravated by the political mistrust among countries in the region. In the present atmosphere of conviviality, platforms of cooperation like SAARC offer scope to set in place new institutions that can work towards solving and mitigating some of the more persistent environmental problems.

A sign of encouragement has been the trust that Bangladesh and India have shown in resolving citizenship issues in the exchange of enclaves that took place in 2016. Similar trust is needed in resolving issues relating to migration, human trafficking and internal security problems. 2) State Security - the cooperative states are more concerned about their state securities than transcending the limitation to realize collective human security. Experts have observed that progress on the economic front has been held hostage to the misplaced security concerns of the member nations as foreign policy expert Muchkund Dubey argues: Economic integration in south Asia has remained a non-starter even after 22 years of the South Asian Association for Regional Cooperation. The misplaced and exaggerated security concerns of India and Pakistan are a huge hurdle. The emphasis in these countries needs to shift from state security to human security. It is the need of the hour that the concept of sovereignty has to be expanded to accommodate the changing global scenario where the new norm is that threat to a country emanates from actors in operating in a different country. In recent times, India and Myanmar did a joint operation which allowed Indian Military to operate in Myanmar. However Myanmar has turned down request for anymore such joint operations. Therefore, there is a need of the collective intentional stance to be developed on certain issues which require greater maturity on part of the member states.

\section{PARADIGM SHIFT: FROM GDP TO GNH}

Elizabeth Allinson in her paper captures the rationality of the Gross National Happiness or GNH; the thought provoking idea that offers an alternative to the standard GDP method as an indicator of national development in general and human development in particular. She writes: 
"The Himalayan nation of Bhutan has been a leader in devising and promoting an alternative development paradigm called gross national happiness. The king's statement "Gross National Happiness is more important than Gross National Product" arose from Buddhism, which recognizes the transitory nature of material satisfactions. This view, together with the findings of positive psychology, is encouraging Western nations to measure the full spectrum of human well-being". Working on the traditional Buddhist philosophy of "Vajrayana", the fourth king of Bhutan when faced the challenge of growth and development, designed a new but an effective standard of human well being and quality of life. Instead of following the GDP model he developed his own alternative which later on became the exemplary for the whole world to understand the human development from another perspective: The Human Happiness. On the contrary to the model of production, consumption and materialism, Bhutan envisaged the human development through qualitative higher happiness. They designed their own model based on the four pillars: 1) Sustainable and Equitable Socioeconomic Development, 2) Environmental Conservation, 3) Preservation and Promotion of Culture, and 4) Good Governance. Bhutan the founder of the Gross National Happiness (GNH) attracted the eyeballs of the whole world to the basic human desire that is well defined since ancient times by great philosopher Aristotle that we all human desire happiness by the very nature. Why we need development only to feel happy with sense of personal growth, basic facilities and security, but if the economic development cannot bring the happiness to the common people then we should reasonably revise the standards of the developments. This is where the GNH focused on "Value Based Development". Elizabeth Allison so neatly defines: Gross national happiness offers a way to understand national progress that incorporates an ethical function and values the intangible aspects of human life that are much of what provides vitality and well-being. It shifts consciousness away from the continual pursuit of more, bigger, and better-goals that are now well-known to be unsustainable and highly destructive to the surrounding environment - and toward goals that can satisfy human cravings for meaning, connection, value, and worth. In suggesting that happiness is more important than any product, GNH helps us consider what material goods might be enough, and what sufficiency rather than overabundance might mean for our lives, our homes, and our ecosystems.

Aristotle in his theory of Eudemonia talks about the human flourishing, social welfare and well-being. The theory is better realized when we take up the human development from the view point of different development consciousness. Taking an ethical turn to critically asses the dynamics of development, we can say we need that kind of schema in which the psychological well being of people is pursued with the same vigor as the material well being. The model should be satisfying the material, emotional and spiritual needs of the human beings.
The GNH philosophy as a standard of development is followed as a model to achieve the human happiness and is worldwide realized as Allinson wrote in her paper: Countries around the world, including the United States, have begun experimenting with their ideas about GNH. While GNH arose from Buddhist roots in Bhutan, it aligns closely with the science of well-being, as well as recent studies of positive psychology and the economics of happiness. Western European countries have led the international movement toward adopting GNH. In 2009, French president Nicolas Sarkozy announced a plan to make happiness a key indicator of growth, and requested that Nobel Prize-winning economists Joseph Stiglitz and Amartya Sen to develop measures to incorporate wellbeing into national assessments. Following France's lead, British prime minister David Cameron called on economists and policy makers to focus on "GWB," or "general wellbeing, "by polling 200,000 people about the state of their happiness."In the Americas, the "Genuine progress indicators" or the GPI method adopted by Nova Scotia, Canada, which has been a leader since 1997 in identifying new measures of sustainability, well-being, and quality of life - is a path breaking approach as it goes beyond the one-dimensional measures of GDP. Not surprisingly, the Founder and executive director Ronald Colman attended the first two GNH conferences to advise the Bhutanese on developing GNH indicators. Growing interest in GNH prompted Brazilian policy makers to introduce a bill to amend Brazil's Constitution, making the quest for happiness an inalienable right, in early 2011.Six residents of the US state of Vermont attended the fourth GNH conference in Bhutan and were inspired to launch Gross National Happiness USA (GNHUSA) in spring 2009. The group's initial work focused on raising awareness of GNH, gathering information, and connecting interested people. To kick off the national movement, GNHUSA held a conference in Vermont entitled "GNH 2010: Changing What We Measure from Wealth to Well-Being."

It is evident that the appeal of the GNH model has grown manifold and is attracting converts by millions. Even the United Nations has accepted that the methodology followed by it does not have the ability to capture the real well being of the people. In its resolution 65/309 in 2012, the UN General Assembly recognized the inadequacy of the GDP as an indicator of the gross well being of the people. As far as the physical well being is concerned, the importance of which cannot be gainsaid, the parameters of UNMDG are capable of indicating how far governance of a particular country has succeeded in combating the ills that have plagued them. The eight development goals in the areas of poverty, education, gender equality, child mortality, maternal health, infectious diseases and environmental sustainability are extremely relevant for the SAARC nations as we have a poor track record in these areas so far. Our governance has been less than successful in delivering progress in the above fields. The idea of GNH goes hand in hand with the Millennium Development Goals as without the one, the attainment of the other is difficult. GNH is not 
opposed to but complementary to UNMDG and merely expands the scope of the MDGs. In the light of these MDGs let us turn to the challenges that the SAARC region faces.

\section{CHALLENGES TO GROSS NATIONAL HAPPINESS (GNH) OF SAARC}

The hopes of SAARC have largely been belied. It has not lived up to the expectations on any front. The potential for transformation that it promised has largely been squandered away. The platform has been mostly a cosmetic affair only serving the purpose of bureaucratic interaction without any tangible goals. The resolve and the intent of the governments have also been circumspect. Before it meets the fate of many of the past organizations which are now long forgotten and defunct, some intent and determination has to be injected in this forum. The onus of this is largely on India which is the largest member by all standards. The invitation extended by the PM to invite SAARC heads to his inauguration ceremony was a welcome move. It portended a revitalization of SAARC, a symbolic gesture to put it back on the pedestal that it once occupied. It is all the more important because over the last three decades since the inception of SAARC, the world has transformed beyond recognition. The rest of the world has marched ahead in spectacular way while we have remained stuck or even regressed. SAARC has to adapt itself to the globalised world and rejuvenate itself. It has been plagued by a plethora of challenges to which adequate solutions are yet to be found. On that depends the well being of its people, their Gross National Happiness. Let us turn to these challenges and see how SAARC can confront them.

\section{A. Challenges of Democracy}

The development of a region essentially means that the people of the region are able to live in peace and dignity and which gives them the capacity to fulfill their potential. To provide such an atmosphere is the ultimate aim of all governments. Part of the solution is the betterment of material conditions of the people. But even more important is providing the freedom and chance to let the citizens pursue their dreams. The political ethos of the countries matters a lot in achievement of this aim. Fortunately democracy in its various forms is already established in this region. There have been threats to the democratic form of government at times in some nations but sooner or later democracy has triumphed. However the spirit of democracy has not always been followed even in the nations that have elected governments. Majoritarianism has been on the rise in most of the nations, excepted India. Minorities have been under some sort of fear in some countries. There has been a spate of attacks on agnostics and minorities in Bangladesh recently. Persecution of minority Christian and Hindus is also becoming more common in Pakistan. These tendencies have to be curbed if we are to move towards a healthier and progressive region. Strengthening of democratic institutions is a must.

\section{B. Challenges of Human Rights}

The sanctity of human rights has to be guaranteed and protected at all costs. The south Asian region comprises the most populous region in the world, greater than China. The stark poverty under which most of the population lives already makes their life full of hardships. Under such dismal material conditions, an oppressive state or a loss of rights can make life a veritable nightmare for these hapless people. The resilience of South Asian people is incredible. There is an innate optimism that one comes across in the poverty ridden population of South Asia. They are bubbling with enthusiasm and have never despaired of a better future. This unbounded enthusiasm is the greatest tribute to the democratic spirit of this region which believes in equality of opportunity for all. It is the assurance that the states will guarantee and respect the human rights that gives the powerless the courage and the strength to chase their goals. However in recent time's incidents of human rights abuse has been on the rise. If South Asia is to become a region of peace and prosperity, SAARC has to become a watchdog which ensures that Human rights violations do not take place. SAARC's past track record has been less than satisfactory in this regard.

\section{Challenges of Poverty and Inequality}

SAARC countries together account for $40 \%$ of the world poor. This is a statistic that is too devastating to be missed. In an integrated world of today, it is a concern not just for the SAARC countries but for the world as a whole that despite spectacular technological and economic progress so many people remain mired in poverty. It puts severe strain on the resources of the earth. SAARC nations have to urgently get their act together to ensure that this figure is reduced or else the threat of poverty and its attendant disastrous consequences will engulf the whole world. China has shown the way to the world how millions can be lifted out of poverty in a span of decades. Economic development through economic cooperation is the way forward. Not much progress has been achieved on these fronts. Economics continues to remain hostage to politics and regional interests thereby depriving millions of the benefits. India in particular has a huge responsibility in this regard being the largest economy in the region. It is to India's benefit if the Inter regional trade increases.

\section{Challenges of Ecological Degradation}

The subcontinent faces enormous ecological challenges which are exacerbated by the fact that all the SAARC nations are developing countries who have energy needs disproportionate to their resources and capital. Global Warming can have disastrous consequences for the SAARC region unless concerted action is taken to meet economic goals in a sustainable manner. The countries share a natural ecological space and actions of one nation can affect the vulnerable ecosystems of the other. Recently we have seen cataclysmic events in the Himalayan region in Kedarnath 
which resulted in enormous loss of lives. There is compelling logic for intensified cooperation in this arena of eco conservation. More importantly, on the climatic pattern depends the monsoon which is the most important natural phenomenon on which the whole economy of the region depends. SAARC can neglect environment only at its own peril.

\section{E. Challenges of Militarization}

Ever since SAARC's inception, the cynics have always doubted its efficacy because of the political and military rivalry between India and Pakistan. Sadly, it seems that they have been justified in their prognosis. The agenda of IndoPak relations has always hijacked the actual issues of development. The limelight of any SAARC meeting is the handshake between the Prime Ministers of India and Pakistan. . The piling up of nuclear arms in the name of deterrence which in turn is based on the tenuous theory of MAD (Mutually Assured Destruction) goes against the very tenets of SAARC. A fifth of the world's population lives in a perpetual fear of a holocaust. Securing Peace will require some radical thinking from the governments and some statesmanship rather than one-upmanship and playing to the galleries from our politicians. How can there be an increase in GNH when perilous destruction is always looming on our heads?

\section{F. Challenges of Women's Rights}

Women in South Asia are one of the most vulnerable groups. Incidents of Female infanticide, gender discrimination, atrocities on women are so frequent in SAARC countries that the people have almost accepted this state of affairs. Though there have been activists in all the countries speaking up against these scourges, the ground reality are still far from satisfactory. The entrenched patriarchy in the South Asian mindset has to be somehow changed and female participation in the society has to be increased. Organisations like Sewa have done incredible work in bringing the South Asian women closer to each other. As Rema Nanawaty describing the plight of women in South Asia eloquently puts it "Rarely have women faced light and darkness, prosperity and poverty, hope and loss juxtaposed with each other as in this region. SAARC needs to do much more than what it has done so far to alleviate women's problems in this region. Making them financially self reliant, providing them with legal means to redress their grievances, adequate security etc. some of the ways in which women can be empowered.

\section{G. Challenges of Terrorism}

Post 9/11 the South Asian region was transformed like never before. The repercussions of the American invasion of Afghanistan were faced by the entire South Asian region. It became one of the most terrorism infested areas of the world. Afghanistan and Pakistan, became hotbed of terrorist activity. Pakistan in particular became a safe haven for terrorists and the areas adjoining Afghanistan became almost the fiefdom of the terrorists. These safe havens were used by the Al Qaeda and the Haqqani networks to launch terror attacks in various parts of the world. America in particular has time and again asked Pakistan to dismantle the terrorist network operation within its boundaries. Unfortunately, the Pakistani establishment finds itself powerless to eliminate these elements try as much as it may. Pakistan has bore the brunt of terrorism and is currently reeling from the violence that has become routine in that country. It will serve no purpose to keep pointing fingers at Pakistan as the genie it created has become a monster which threatens to eat its master. To eliminate terrorism, concerted action by all the countries is required. The meeting of Home ministers in Islamabad was one such move. However as mentioned earlier differences cropped up which served no purpose. It is the responsibility of each member of SAARC to assist Pakistan in slaying this dragon of terrorism. Pakistan in turn must show real determination and intent to fight terrorism in all forms without distinguishing good and bad terrorism in the manner that it has done so far.

\section{THE UNIQUENESS OF SOUTH ASIA AND THE ALTERNATIVE: GROSS SAARC HAPPINESS (GSH) MODEL}

Few geographical regions of the world have the cultural richness and an innate bonding based on shared values as the South Asian region does. Despite the plurality of traditions and cultures, all South Asians feel that we share a common heritage, a heritage that is unique and that sets us apart from the rest of the world. This includes not just our historical ties and interactions but also a commonality in the way we are a part of the globalised world. The development of this region will require more vibrant people to people, culture to culture, organisation to organisation interaction. SAARC has a huge role to play in facilitating this transition.

The challenges that we face can lead to pessimism which would be uncalled for. It is how we meet these challenges that determine the future course of SAARC. We have to adopt a synergetic approach to tackling these problems. On the one hand we have to accelerate the economic development in a sustainable, time bound way so that the ills of poverty and inequality are eradicated. On the other hand, we want to do it keeping in view that in pursuit of these goals we leverage our cultural and civilisation heritage. The Gross National Happiness model has to be further chiselled and adapted in the context of South Asian. The way to move forward for the SAARC region would be the Gross SAARC Happiness model or the GSH way. The GSH model resembles the GNH model in all ways except that it relies more heavily on the second pillar, "the Preservation and promotion of cultural values" and pins its hope on this to bring about a change in all other spheres. The only way this can be achieved is by letting the social and cultural wisdom of the region - what can be termed as the Socio-Cultural Capital-perform the miracle. Each region, each people, has its own unique strength, its own 
unique identity, and the unique strength and identity of the Indian Subcontinent is the shared values that they have inherited which places more importance on inner peace, contentment, beauty, joy and truth. According to our shared tradition, the pursuit of external happiness has only been sanctioned, if it is in harmony with our inner goals, never at its expense. The ever growing reliance on increase in GDP or a better economic growth rate, as if a change of a decimal percentage point in our growth rate will somehow elevate a whole nation to a region of paradise, is a mirage, an illusion, as the evidence clearly points out that it is accompanied by a host of social, cultural, environmental and psychological problems. In our pursuit of economic growth, in which we have recorded dismal growth anyway, we have lost track of the inner direction as well. We are losing both ways. Better arrest this degradation sooner than later. Hence, the need for an all inclusive model which GSH offers.

This requires jettisoning the mindset that believes that only governments are capable of providing solutions for a country and that only political class has the power and the capability to create such changes. This greatly underestimates the capacities of people of a nation and somehow implicitly believes in the Hobbesian approach to society which believes that human beings are by nature inclined towards conflict. This worldview has to be shed and the innate goodness of the human heart, the Bodhichitta or the Wisdom Heart dormant in every human being as the Buddhists say, has to be awakened. This can only be done if the cultural and traditional wisdom of the region, the second pillar of GNH, is allowed to bring about the transformation needed, both in the outer world and the inner world. Real change can only come when the people transcend the artificial divisions of state, faith, race and the like and come together for a common purpose solely motivated by a determination to create a better future together.

As indicated earlier, a deeper understanding of the south Asian ethos which will enable us to overcome the problem. The way to an enhanced GSH is to tap the potential of our shared cultural and civilization heritage and values. More than economic cooperation to which somehow only lip service seems to have been paid by SAARC in the last three decades, we need to engage the heart, mind and souls of the people. This will require a concerted effort to bring the people of the eight nations together. It is easier said and done because one of the anomalies of the region is the lack of trust between different countries due to festering issues. A new way of looking at the world of today, a globalised world is needed.

The Machiavellian conception of a world perpetually at war has to give way to the Buddhist conception of a world striving for peace and happiness. The old world paradigm of military superpower is now more and more being relegated to the background. We hear a lot about economic superpower but in days to come we will be hearing more and more of countries aspiring to become Happiness
Superpower. South Asia has the potential to become a Happiness Superpower.

SAARC can tackle the above mentioned challenges with a new focus, a new consciousness. This geographical region has a rich tradition of transcendence of the ego and of living harmoniously with nature. An acknowledgement of the fact that the pursuit of economic growth with a view to attaining the consumption levels of western countries is neither possible nor advisable. The people of South Asia have been known for their contentment. Despite living in miserable condition, an inner reservoir of optimism is always visible on the faces of people. They do not demand a life of opulence and luxury. The psyche of this region, shaped by the teachings of great men like Buddha, Mahavir and Gandhi seeks some higher purpose, almost a call of the spirit once their basic needs are met. Despite rapid urbanisation in recent times, a vast majority still lives in the rural areas where simple pleasures of life enrich their soul. An extremely rich tradition of mythology and folklore exists in all these countries which is a source of much happiness. Art, music, literature, cinema, sports etc. have ample scope of dissolving much of the differences we hear about all the time. An Indo Pak match does more to achieve bonhomie in the relations between these two countries than several rounds of diplomacy. It is a much deeper cooperation and integration in these areas that is called for. The People's SAARC movement is one such movement whose potential is yet to be tapped. In response to the recurrent failures of the current regimes in South Asia to address the pressing challenges of the region, The People's SAARC has positioned itself as an alternative movement which aims at self reliance and reposes faith in the inherent capability of people to come up with radical solutions to their problems without resorting to the governmental mechanisms. It is aimed at celebrating the similarities that bind this region. Since the opening of its first chapter in Kathmandu in 2007, it has mobilized the youth of the SAARC nations in an unprecedented manner. The voice of millions which was never heard in the din and bustle and glare of the political forums now has a chance to be heard. It has set out its agenda in clear terms- empowering people to come up with their own solutions rather than relying on government aid. Because of its trenchant criticism of the existing SAARC regimes, it is unlikely to garner much support from the powers that be, thin skinned as the politicians are in the face of criticism. It will be a test of their intent to bring real change and their open mindedness if they can provide financial and political support to a movement that came into being in response to their failure. There has to be some kind of an acknowledgement on part of governments that they have been consistent underachievers in the past and the situation is unlikely to change if broader participation of people is not encouraged, an area where People's SAARC can do incredible work. As mentioned earlier, the greatest asset of the region is its Social and Cultural Capital rather than the financial or economic capital. The dividends that the Social capital can yield are multifold. 


\section{CONCLUSION}

We have seen so far that the goals of SAARC have only been partially met and there is an enormous ground to be covered. The movement has lost its momentum and has largely become a political and bureaucratic exercise. Though some headway has been made on the economic cooperation front by the establishment of SAFTA and the easing of intra regional business, it has not translated into any meaningful benefit for the population as a whole. Similarly, on the political front, the contentious issues, barring a few exceptions, continue to remain unresolved despite being discussed in every SAARC meetings since its inception. The achievement of SAARC Developmental Goals (SDGs) formulated on the lines of UN Millennium Development Goals appears to be a distant dream.

The people of the region have been victims of poor governance which has only marginally benefitted them. We have also seen that the alienation of the people from the process has been one of the major drawbacks of SAARC. Relying solely on the financial and economic capital, they have so far neglected to leverage the most powerful potential agent of transformation of this region- the Social and Cultural capital. The concept of GNH which lays great stress on this aspect of development is therefore the ideal model to be adopted by SAARC. In the context of South Asia, it can be further realigned so that we have GNH tailormade for South Asia in the form of GSH. The fundamental idea of GSH is the transformation of the region by relying on more people to people interaction and empowering them bring about the desired change.

It goes without saying that the solutions require out of box thinking or lateral thinking. Many a times we commit the mistake of tackling a problem head on and hope that remaining pre occupied with the problem alone will generate the solution. It was Einstein who said that "the mind that created the problems cannot be the same mind which will come up with the solutions." If we are to move into the direction of becoming a happiness Superpower, unthinkable as it may seem given the prevalence of so many problems, we have to start imagining the unimaginable. What can be done to bring people closer to one another? Why can't we have a South Asian Union on the lines of the European Union (EU)? Why can't we have completely hassle free movement of people without visa or passport? Why can't we have a Common Bank for SAARC countries? Why can't a Film fare award be held in Karachi? Why can't we have a Trans national anthem for South Asia which schoolchildren can sing? The need of the hour is to unshackle the region from the grips of politics and let there be an intermingling of people. It is unthinkable what a mass of 1.4 billion people having goodwill in heart can achieve provided an atmosphere of trust is built and they are given the power and the freedom to decide for themselves.

\section{REFERENCES}

[1] Allison, \& Elizabeth. (2012). Gross National Happiness, Retrieved from https://www.academia.edu/6227393/Encyclopedia_of_ Sustainability_Gross_National_Happiness.

[2] Dennett, D. (1971). Intentional Systems. The Journal of Philosophy, 68(4), 87-106.

[3] Habib, \& Meer Ahsan. (2016, April 25). GDP or Happiness. Retrieved from http://www.thedailystar.net/op-ed/economics/gdp-orhappiness-1214482.

[4] Hussain Akmal, (2016). South Asian Cooperation: Towards a Humane World. In Rijiv Kumar \& Amita Goyal (Eds.), Thirty Years of SAARC: Society, Culture \& Development (1st ed., pp: 65-77). Sage Publication India.

[5] Kalegama Saman. (2016). Challenging Face: The Trails and Fortunes of Regional Cooperation under SAARC. In Rijiv Kumar \& Amita Goyal (Eds.), Thirty Years of SAARC: Society, Culture \& Development, 1st ed., 25-41. Sage Publication India.

[6] Kothari, A. (2013). Development and Ecological Sustainability in India: Possibilities for the Post-2015 Framework. Economic and Political Weekly, 48(30), 144-154. Retrieved from http://www.jstor. org/stable/23527999.

[7] Lempert, D. (2017). Testing the Global Community's Sustainable Development Goals (SDGs) Against Professional Standards and International Law. Consilience, (18), 111-175. Retrieved from http://www.jstor.org/stable/26188797.

[8] Ludden, D. (2005). Development Regimes in South Asia: History and the Governance Conundrum. Economic and Political Weekly, 40(37), 4042-4051. Retrieved from http://www.jstor.org/stable/4417144.

[9] MAY, L. (2013). A Hobbesian Approach to Cruelty and the Rules of War. Leiden Journal of International Law, 26(2), 293-313. doi:10.1017/S0922156513000058.

[10] Muchkund Dubey. (2007). SAARC and South Asian Economic Integration. Economic and Political Weekly, 42(14), 1238-1240. Retrieved from http://www.jstor.org/stable/4419435.

[11] Nanavaty Reema. (2016). Sewa's Sister to Sister Initiative for Peace and Work. In Rijiv Kumar \& Amita Goyal (Eds.), Thirty Years of SAARC: Society, Culture \& Development, 1st ed., 176-182. Sage Publication India.

[12] Obino, F. (2009). SAARC: The Political Challenge for South Asia and Beyond. Economic and Political Weekly, 44(9), 118-125. Retrieved from http://www.jstor.org/stable/40278560.

[13] Rodrigo Nihal. (2012). Emerging Asia, SAARC and Regional Cooperation, Pluto Journals, 9(1), 49-55. Special Issue: China and SAARC.

[14] Sharan, \& Shyam. (2016). South Asia's Mounting Ecological Challenge: Regional Cooperation is the Only Answer In Rijiv Kumar \& Amita Goyal (Eds.), Thirty Years of SAARC: Society, Culture \& Development (1st ed., 53-64). Sage Publication India.

[15] Smith, T. (2000). The Audience of the Nicomachean Ethics. The Journal of Politics, 62(1), 166-186. Retrieved from http://www.jstor. org/stable/2647602.

[16] Sparham Gareth (1992). Indian Altruism: A Study of the Terms bodhichitta and bodhichittotpada, The Journal of the International Association of Buddhist Studies, 15(2), 224-243.

[17] Sugden, R. (1993). Welfare, Resources, and Capabilities: A Review of Inequality Reexamined by Amartya Sen. Journal of Economic Literature, 31(4), 1947-1962. Retrieved from http://www.jstor.org/ stable/2728332.

[18] Jha, U. C. (2004). Environmental Issues and SAARC. Economic and Political Weekly, 39(17), 1666-1671. Retrieved from http://www. jstor.org/stable/4414925.

[19] Ura, K. (2005). Gross National Happiness. Sociological Bulletin, 54(3), 603-607. Retrieved from http://www.jstor.org/stable/23620628

[20] William D. Nordhaus (1994). Do Real Output and Real Wage Measures Capture Reality? The History of Lighting Suggests Not, Cowles Foundation Discussion Papers 1078, Cowles Foundation for Research in Economics, Yale University. 